\title{
MEDICAL AND SOCIAL PROBLEMS OF EXTRAMARITAL BIRTHS
}

\author{
S. Garov ${ }^{1}$, D. Gugutkov ${ }^{2}$, V. Garov ${ }^{3}$ \\ ${ }^{1}$ Faculty of Public Health, Medical University - Sofia, Bulgaria \\ ${ }^{2}$ Multi-profile Hospital for Active Treatment "Doverie", Sofia, Bulgaria
}

\begin{abstract}
Results of the conducted empirical study provide a basis to make a scientifically reasoned conclusion that the extramarital birth rate still poses specific problems to both the individuals and the society as a whole. In order to solve these problems, the need for targeted activity of government institutions and the whole society to support and motivate young people so they change their reproductive behavior and decision-making in accordance with the social norms, becomes more and more imperative.
\end{abstract}

Key words: newborn babies, extramarital pregnancy, single mothers

\section{INTRODUCTION}

The tendency of the comparatively stable growth of the relevant share of extramarital births is in accordance with the change from the traditional family model of marriage to free cohabitation on common law basis. $(1,2)$ The new family model changes also the family relations and the place and the role of the family in the society towards a decrease in their economic, social and traditional value, weight and importance. $(3,4)$

The reasons for the change in the attitude towards free cohabitation and extramarital births are many and interconnected, but the most important ones can be summed up as follows: economic - aim towards economic (earnings-based) independence of women and fear of becoming dependent at their most vulnerable period (child-birth and raising a small child); educational - completing higher education levels; professional and career gaining recognition in the profession and career growth; social-psychological - presence of a proper partner; availability of autonomous dwelling, affordable services for raising, teaching and supporting the education for the kids. $(5,6,7)$

\section{PURPOSE}

The purpose of the survey is to make a

*Correspondence to: Svetoslav Garov, Department "Medical pedagogy", Faculty of Public Health, Medical University - Sofia, Sofia 1527, No.8 Byalo More Str., email: sv.garov@gmail.com comparative analysis of the medical and social characteristics between single mothers and married mothers through a questionnaire.

\section{METHODS}

The survey was carried out in the city of Sofia from 01.01.2016 to 30.06. 2017. To achieve its purpose an empirical survey through a questionnaire was carried out among 108 single adult mothers and 108 married mothers in the First Specialized Hospital for Obstetrics and Gynaecology Sveta Sofia EAD, the Second Specialized Hospitals for Obstetrics and Gynaecology Sheynovo, the University Obstetrics-Gynaecology Hospital Maychin Dom. Women in childbirth were surveyed from the 3rd to the 5th day after birth, which lowered the embarrassing influence of the birth process on their mental condition.

\section{RESULTS}

\section{Health status of single mothers}

Defining the women who have given extramarital birth in a series of studies as a "risk group", which means there are substantially higher rates of pathology among them, directed the survey to studying the health status of the respondents - women who have given extramarital birth. $(8,9)$ For this purpose were used data from the records kept in the birth facilities.

The medical data of the mothers covered by the survey from the two compared groups for the time before the pregnancy occurs revealed important differences in relation to previous 
GAROV S., et al.

illnesses, gynaecological history and voluntary abortions. The legal abortion is still accepted and often used as a preferred and affordable escape from unwanted pregnancy, although there are known dangers and harms to the health and child-bearing ability of a woman who has undergone such an intervention. The data of the survey show that:

$>$ voluntary abortion is twice as common in single mothers $(18,5 \%)$ than in married mothers $(8,3 \%)$;

$>$ single mothers also experience pathology of pregnancy more often than the controlled group of mothers.

The reasons for the mass practice of abortion in the Bulgarian society as a means of controlling birth and escaping from unwanted pregnancy can be found in the low degree of contraceptive and sexual awareness of the population, recreating moral norms for admissibility and absence of moral sanctions against abortion, recreating old stereotypes and norms for the responsibility and blame in the intimate relations of the man and the woman, expensive modern contraceptives, etc.

The early morning sickness of pregnancy are more common in extramarital mothers $(10.2 \%)$ than in controlled married ones $(3,7 \%)$. Especially strong impression was the underlined difference between the relative share of extramarital mothers $(6,5 \%)$ and married women $(2,8 \%)$ who have been diagnosed with nephropathia gravidarum. The differences between the two groups are statistically significant $(\mathrm{P}<0,001)$.

\section{Health status of extramarital newborns}

The survey determined statistically significant differences $(\mathrm{P}<0,001)$ between extramarital newborns and marital newborns regarding the signs characterizing their health status:

$\checkmark$ The preterm neonates among the extramarital newborns are $22-20,4 \%$, while their number among marital ones is $7-6,5 \%$.

$\checkmark$ First degree of prematirity is seen in 9,3\% of extramarital babies and in $4,6 \%$ of marital babies.

The results of the survey reveal that while the values of the physical development indicators of marital newborns coincide with the average values of these indicators for the country, those related to extramarital newborns are much lower. No statistically significant difference by gender and physical development for both groups was identified. A series of surveys of the sociological and medical aspects of the extramarital pregnancy reveal the existence of a direct correlation between poor living conditions and the low weight of extramarital newborns. The survey could not determine statistically significant differences between the earnings of the two compared groups of mothers during their pregnancy, as well as some over-population with extramarital pregnant women, which influence the health of the babies they give birth to. Aside from that, the method used for the control group, as well as its standardization by the mother's age and the child's number in succession, provided an opportunity to study the influence of extramarital pregnancy on these indicators, shown mostly in the attitude and behaviour of the extramarital pregnant woman to her pregnancy.

When studying the behaviour of a single mother, it was established that a large percentage of them have smoked during their pregnancy. About $1 / 4$ of them have smoked more than 5 cigarettes a day, which is definitely harmful for the foetus growth and development. Some authors note a direct correlation between the low weight at birth and the amount of cigarettes smoked. This fact is explained with the effect of nicotine, which reduces the blood flow to the foetus causing a spasm of the vessels of the placenta and thus lowering the supply of nutrients, which leads to delayed development. On the other hand, smoking has a direct toxic effect on the foetus.

Another harmful factor is the consumption of alcoholic drinks. The results of this survey show that there are single mothers who have frequently consumed alcoholic drinks. Moreover there is a trend of preference of strong drinks, which have immediate toxic effect on the development of foetus.

It is necessary to point out the large number of attempts among single mothers to interrupt their pregnancy. (10) In their attempt to hide the unwanted pregnancy from relatives or to remove it as soon as possible, many of them have used different mechanical devices as well as drugs causing uterine contractions. All of these failed attempts had a negative impact on the health of the newborn. Many clinical studies and special surveys prove that pregnancy-related complications are the main causes of premature birth and lower indicators for the physical development of the newborns.

The analysis of the health status of single mothers in the research shows a higher share of single mothers with nephropathia gravidarum in comparison to the control group of mothers. Late morning sickness as well as anaemia 
during pregnancy negatively affect the foetus development. All that leads to the conclusion that the illnesses during pregnancy that are more common among single mothers compared to married mothers, have had a negative effect on the foetus development.

Another important fact is that voluntary abortion is twice as common among single

Table 1. Voluntary abortion
GAROV S., et al. mothers as among married mothers. The existence of voluntary abortion is one of the main causes for premature birth during the next pregnancy because the anatomic functional damages of the lower uterine segment as a result of the intervention greatly increase the risk of a spontaneous miscarriage. (Table 1)

\begin{tabular}{|l|cr|r|r|}
\hline \multicolumn{5}{|c|}{ VOLUNTARY ABORTION } \\
\hline survey groups & \multicolumn{2}{|c|}{ SINGLE } & MARRIED & \multicolumn{1}{c|}{ TOTAL } \\
\hline & $\%$ & $\%$ & \multicolumn{1}{c|}{$\%$} \\
\hline YES & & 18.5 & 8.3 & 13.4 \\
\hline NO & & 81.5 & 91.7 & 86.6 \\
\hline Total & & 100 & 100 & 100 \\
\hline
\end{tabular}

It is logical to assume that these factors have significantly affected the foetus development, which is expressed by the differences identified by the survey in the indicators for maturity and for the physical development of extramarital children in comparison to the marital ones. There is also a notable difference between the two compared groups regarding the rate of stillbirths and deaths among newborns in the first weeks of their lives. The relative share of stillbirths and death rates until the 7th day after birth among the group of extramarital kids makes a strong impression considering the lack of stillbirths and deaths among newborns from the control group. Two stillbirths and three deaths of extramarital newborns in the first week of their lives were identified.

The great importance of weight at birth is also determined by the fact that physiological immaturity of pre-term neonates and the individual systems of the organism (immaturity of the breathing centre and breathing apparatus, insufficient development of the central mechanisms of thermoregulation, incomplete development of the enzyme systems, etc.) disturb the adaptation mechanisms of newborns, they are inferior and when they need to adapt to extrauterine life, they quickly decompensate. That is why the normal delivery process can have a much more stressful influence on a prematurely born child than on a full-term baby. This explains to a significant degree the impact established by the survey of the prematurity and asphyxiation on the percentage of stillbirths and deaths until the 7 th day after birth for the surveyed cohort of extramarital children.

The analysis of the causes for death of foetus (newborn) in the perinatal period reveals that the main cause are the inborn malformations followed by asphyxiation. This could be explained with the illnesses discovered during the research of the medical history data of single mothers during their pregnancy (a larger percentage of late morning sickness and infectious diseases in single mothers compared to married ones) as well as the different drugs taken by single mothers for the purpose of interruption of the unwanted pregnancy.

The analysis of traumatic injuries during delivery shows that they are more common in extramarital compared to marital children from the surveyed groups. The differences are statistically reliable $(P=0,001)$. The notably larger relative share of pre-term newborns in the group of extramarital newborns determines to a large extent the established significant percentage of asphyxiation among them (Table 2)

Table 2. Traumatic injuries during birth among newborns

\begin{tabular}{|l|r|r|}
\hline \multicolumn{3}{|c|}{ TRAUMATIC INJURIES DURING BIRTH AMONG NEWBORNS (\%) } \\
\hline & $\begin{array}{c}\text { EXTRAMARITAL } \\
\text { NEWBORNS }\end{array}$ & MARITAL NEWBORNS \\
\hline NONE & 71.1 & 84.5 \\
\hline $\begin{array}{l}\text { ASPHYXIATION INTRA } \\
\text { PATRUM }\end{array}$ & 26.1 & 14.4 \\
\hline $\begin{array}{l}\text { BIRTH TRAUMAS WITHOUT } \\
\text { INJURIES OF BRAIN AND } \\
\text { SPINAL CHORD }\end{array}$ & 2.8 & \\
\hline
\end{tabular}

Trakia Journal of Sciences, Vol. 16, Suppl. 1, 2018 


\section{CONCLUSIONS}

In the process of decision-making by assessing and choosing the direction of their behaviour in the specific situation, an individual is led by pre-determined and accepted permanent value insights and interests. The value insights are an expression of a deeply thought out and permanently fixed line of behaviour. The value insights determine the circle of opportunities that an individual has to control themselves, their feelings and moods, to choose freely different forms of behaviour.

The obtained results of the survey coincide to a large degree with the literature data and confirm the medical and social problems that follow extramarital birth.

The researchers that have studied this question note higher indicators of still-births and early neonatal mortality among extramarital kids compared to the marital ones. They also point out that the weight of the newborn is one of the main factors determining perinatal mortality.

\section{REFERENCES}

1. Ministry of Labour and Social Policy. Updated national strategy for demographic development of the population of the Republic of Bulgaria, S., pg.151, 20122013

2. Doyle, R. Going solo. Unwed motherhood in industrial nations rises. Scientific American. 286 (1); 24, 2002
3. Ford-Gilboe, M. Dispelling myths and creating opportunity: a comparison of the strengths of single-parent and two-parent families. Advances in Nursing Science. 23 (1): 41-58, 2000

4. Franz, M. et al. Psychological distress and socioeconomic status in single mothers and their children in a German city. Social Psychiatry \& Psychiatric Epidemiology. 38 (2): 59-68, 2003

5. Stoilova, R. Sociological aspects of female health. Social Medicine, 4, 10-12, 2002

6. Cairney, J. \& Wade, T.J. Single parent mothers and mental health care service use. Social Psychiatry \& Psychiatric Epidemiology. 37 (5); 236-42, 2002

7. Dickinson, A. The single life. Time. 157 (21); 92, 2001

8. Dworkin, J.B. \& Larson, R. Age trends in the experience of family discord in singlemother families across adolescence. Journal of Adolescence. 24 (4); 529-34, 2001

9. Jaffee, S.R. et al. Life with (or without) father: the benefits of living with two biological parents depend on the father's antisocial behavior. Child Development. 74 (1): 109-26, 2003

10.Ellison, M.A. Authoritative knowledge and single women's unintentional pregnancies, abortions, adoption, and single motherhood: social stigma and structural violence. Med Anthropol Q. 17 (3): 322-47, 2003 